\title{
53rd Annual Meeting of the Society for Research into Hydrocephalus and Spina Bifida Hugh Richards ${ }^{1,2}$ and Deborah Sival*1,3
}

\author{
Address: ${ }^{1}$ Honorary Publication Secretaries, SRHSB, ${ }^{2}$ Neurosurgery Unit, Box 167, Addenbrooke's Hospital, Cambridge CB2 0QQ, UK and \\ ${ }^{3}$ Department of Neurology, University Medical Center Groningen, University of Groningen, Hanzeplein 1, PO Box 30001, 9700RB Groningen, \\ The Netherlands \\ Email: Hugh Richards - hkr10@medschl.cam.ac.uk; Deborah Sival* - d.a.sival@bkk.umcg.nl \\ * Corresponding author
}

from 53rd Annual Meeting of the Society for Research into Hydrocephalus and Spina Bifida Belfast, UK. 24-27 June 2009

Published: 27 November 2009

Cerebrospinal Fluid Research 2009, 6(Suppl 2):SI doi:I0.II86/I743-8454-6-S2-SI

This article is available from: http://www.cerebrospinalfluidresearch.com/content/6/S2/SI

(C) 2009 Richards et al; licensee BioMed Central Ltd.

The 53rd Annual Meeting of the Society for Research into Hydrocephalus and Spina Bifida was held at Queen's University in Belfast, Northern Ireland at the invitation of the local organizing committee; Stephen Brown, Nan Hill, John McCann, Alan Bailie, David Marshall, Tabib Dabir, Emma Kelly and Marie McGonnell.

Proceedings began as usual on Wednesday afternoon with the Annual General Meeting of Members. This was followed by a reception for all delegates and guests where we were welcomed to Belfast by the Lord Mayor, Councillor Naomi Long.

The scientific programme was opened by a welcome from Dr. Michael McBride, Chief Medical Officer for Northern Ireland, and included sessions on 'Spina Bifida: Incidence, Survival and Cognitive Outcome', 'Hydrocephalus', 'Animal Studies', 'Hydrocephalus Shunts', 'Long Term Management of Spina Bifida Patients', 'Urology and Bowel Management' and 'Spina Bifida'. We also had two Invited Lectures, firstly from Neil Buxton (Liverpool, UK), on 'Pain Management in Spina Bifida: a Neurosurgical Perspective' and from Professor Sivert Lindström, (Linköping, Sweden) on 'The Bladder Cooling Test in Spina Bifida'. Retiring President, Professor Ray Fitzgerald (Dublin, Ireland) gave his valedictory lecture entitled 'Here and There with Hydrocephalus', describing changes in treatment he has witnessed through his long and distinguished career. Friday morning's programme included a parallel break-out session on 'Long- term Management of Children with Spina Bifida', aimed at Nurses and Health Care Professionals.

The social programme continued on Thursday afternoon with a visit to the Thompson Graving Dock. This dry dock is where RMS Titanic underwent a final hull inspection in February and March 1912 before final sea trials and sailing to Southampton before sailing on her maiden voyage on Wednesday $10^{\text {th }}$ April. She hit an iceberg on the night of Sunday $14^{\text {th }}$ April and sank with the loss of over 1,500 lives. The afternoon continued with a visit to Stormont, the home of the Northern Ireland Assembly at the invitation of Michael McGimpsey, Minister of Health. We were able to visit both assembly chambers and were then entertained in the Great Hall by Belfast's Open Arts Community Choir, a nationally acclaimed choir featuring people with disabilities and those without, and traditional Irish music from The O'Malley Experience. The final event of the social programme was a gala dinner in the magnificent Great Hall of Queen's University. 